\title{
Anosmia: a COVID-19 symptom that must be investigated by rhinoplasty surgeons
}

\author{
Fabio Maglitto ${ }^{1} \cdot$ Giovanni Salzano $^{1} \cdot$ Luigi Angelo Vaira $^{2} \cdot$ Francesco Antonio Salzano $^{3} \cdot$ Giacomo De Riu $^{2}$
}

Received: 1 June 2020 / Accepted: 2 July 2020 / Published online: 13 July 2020

(C) Springer-Verlag GmbH Germany, part of Springer Nature 2020

The rapid spread of the severe acute respiratory syndrome coronavirus 2 (SARS-CoV-2) infection has led to a change in plastic and aesthetic surgery daily practice. At the present time, many countries in Europe, and the world in general, are starting "phase 2." These regulations provide for a gradual return to normal activities in order to minimize the risk of further infection. In countries like China, which represent the point of comparison because they are at a more advanced stage in the fight against the pandemic, phase 2 has represented a problematic period, not free from complications. Of course, the resumption of post-lockdown activities could easily cause an increase in the number of infections. To overcome such a problem, it will be mandatory to identify asymptomatic patients, basing the diagnosis on their initial symptoms.

The study of the early behavior of the virus and its manifestations may be of fundamental importance in order to achieve this goal. The plastic surgeon, through the anamnestic information collected during the triage procedures, could represent a central figure in this process.

Since the onset of SARS-CoV-2, Mao et al. [1] have analyzed the presence of neurological symptoms in affected patients. The extrapolated data show that anosmia has been present in $5.1 \%$ of cases. As first reported by Vaira et al. [2],

Fabio Maglitto

fmaglitto@gmail.com

1 Maxillofacial Surgery Unit, Department of Neurosciences, Reproductive and Odontostomatological Sciences, University Federico II, Via Pansini 5, 80100 Naples, Italy

2 Maxillofacial Surgery Unit, University Hospital of Sassari, Viale San Pietro 43/B, 07100 Sassari, Italy

3 Department of Medicine, Surgery and Dentistry, "Scuola Medica Salernitana", University of Salerno, Baronissi, 84081 Salerno, Italy chemosensitive disorders have always been observed in patients with COVID-19 in Europe. The first European reports show values ranging from 19.4 to $88 \%$ [3].

The pathogenesis of these disorders is probably related to the infection of the support cells to the olfactory and gustatory receptors, rich in angiotensin-converting enzyme 2 (ACE2) receptors. As demonstrated by our group, in a large multicenter Italian study recently published, chemosensitive disorders have proved to be the first symptom of COVID-19 in 29.2\% of patients and the only one in $9.5 \%$ [4].

The evaluation of olfactory deficits could be useful to screen asymptomatic patients. Wee et al. [5], analyzing selfreported olfactory and gustatory disorders, asserted that they had identified a $95.5 \%$ specificity and $22.7 \%$ sensitivity and concluded that such symptoms should be considered as screening criteria. In agreement with this study, Vaira et al. [6], basing their conclusions on the results of their analysis of quarantined patients, confirmed the possibility of using the detection of such disorders as a valid option for the evaluation of paucisymptomatic COVID-19 cases.

Plastic and aesthetic surgery has suffered a significant suspension of activities during the lockdown phase. However, at the beginning of the epidemic in Italy, an abnormal number of patients attended otorhinolaryngology and plastic surgery clinics due to the occurrence of sudden hyposmia/anosmia, not associated with any other symptoms. Following the onset of fever and coughing, these patients were diagnosed with COVID-19 infection.

In recent weeks, based on the growing number of reports placing these COVID-19 symptoms as the second most frequent after fever, several countries have included chemosensitive disorders in their guidelines for diagnosing SARS-COV-2 infection. Plastic surgeons should be advised that in the case of patients who attend their clinics, reporting changes in their sense of smell and requesting the performance of aesthetic/functional rhinoplasty, suspicion of an ongoing coronavirus infection should be considered in a differential diagnosis. 
Therefore, a careful examination, taking into consideration the findings that have emerged from the first studies on chemosensitive alterations, must be implemented. At present, the lack of any international guidelines means that the aesthetic plastic surgeon must focus his or her attention on all the possible symptoms related to these pathologies. The use of serological tests and swabs could prove decisive in the preoperative evaluation, together with the possibility of obtaining olfactory tasting data. We believe that it is essential that such recommendations are included in the guidelines of the various national plastic and aesthetic surgery associations that will be issued for the resumption of clinical activity during the postepidemic period.

\section{Compliance with ethical standards}

Conflict of interest Fabio Maglitto, Giovanni Salzano, Luigi Angelo Vaira, Francesco Antonio Salzano, and Giacomo De Riu declare that they have no conflict of interest.

Ethical approval This is an observational study, no ethical approval required.

Informed consent This is an observational study, no informed consent required.

\section{References}

1. Mao L, Jin H, Wang M, Hu Y, Chen S, He Q, Chang J, Hong C, Zhou Y, Wang D, Miao X, Li Y, Hu B (2020) Neurologic manifestations of hospitalized patients with coronavirus disease 2019 in Wuhan, China. JAMA Neurol 77:683

2. Vaira LA, Salzano G, Deiana G, De Riu G (2020) Ageusia and anosmia: common findings in COVID-19 patients. Laryngoscope. 130:1787

3. Lechien JR, Chiesta-Estomba CM, De Siati DR (2020) Olfactory and gustatory dysfunctions as a clinical presentation of mild-to-moderate forms of the coronavirus disease (COVID-19): a multicenter European study. Eur Arch Otorhinolaryngol 277:2251-2261

4. Vaira LA, Hopkins C, Salzano G, Petrocelli M, Melis A, Cucurullo M, Ferrari M, Gagliardini L, Pipolo C, Deiana G, Fiore V, De Vito A, Turra A, Canu S, Maglio AA, Serra A, Bussu F, Madeddu G, Babudieri S, Fois AG, Pirina P, Salzano FA, De Riu P, Biglioli F, De Riu G (2020). Olfactory and gustatory function impairment in COVID-19 patients: an Italian objective multicenter-study. Head Neck 42(7):1560-1569

5. Wee LE, Chan YFZ, Teo NYW (2020) The role of self-reported olfactory and gustatory dysfunction as screening criterion for suspected COVID-19. Eur Arch Otorhinolaryngol 277:2389-2390

6. Vaira LA, Salzano G, Petrocelli M, Deiana G, Salzano FA, De Riu G (2020) Validation of a self-administered olfactory and gustatory test for the remotely evaluation of COVID-19 patients in home quarantine. Head Neck. https://doi.org/10.1002/hed.26228

Publisher's note Springer Nature remains neutral with regard to jurisdictional claims in published maps and institutional affiliations. 